\title{
Laboreal
}

Volume $15 \mathrm{~N}^{\circ} 1$ | 2019

Trabalho e cooperação

\section{A cooperação como instrumento de enfrentamento do real: o caso dos magistrados do trabalho no Brasil}

La cooperación como instrumento de enfrentamiento de lo real: el caso de los magistrados en materia laboral en Brasil

La coopération comme outil pour la gestion du travail réel: le cas des magistrats du travail au Brésil

Cooperation as a tool to face the real work: the case of labor judges in Brazil

Ruri Giannini, Laerte Idal Sznelwar, Seiji Uchida e Selma Lancman

\section{(2) OpenEdition}

\section{Journals}

\section{Edição electrónica}

URL: http://journals.openedition.org/laboreal/1202

DOI: $10.4000 /$ laboreal. 1202

ISSN: 1646-5237

\section{Editora}

Universidade do Porto

\section{Refêrencia eletrónica}

Ruri Giannini, Laerte Idal Sznelwar, Seiji Uchida e Selma Lancman, «A cooperação como instrumento de enfrentamento do real: o caso dos magistrados do trabalho no Brasil », Laboreal [Online], Volume 15 $\mathrm{N}^{0} 1$ | 2019, posto online no dia 01 julho 2019, consultado o 14 abril 2020. URL : http:// journals.openedition.org/laboreal/1202 ; DOI : https://doi.org/10.4000/laboreal.1202

Este documento foi criado de forma automática no dia 14 abril 2020.

Laboreal está licenciado com uma Licença Creative Commons - Atribuição-NãoComercial 4.0 Internacional. 


\section{A cooperação como instrumento de enfrentamento do real: o caso dos magistrados do trabalho no Brasil}

La cooperación como instrumento de enfrentamiento de lo real: el caso de los magistrados en materia laboral en Brasil

La coopération comme outil pour la gestion du travail réel: le cas des magistrats du travail au Brésil

Cooperation as a tool to face the real work: the case of labor judges in Brazil

Ruri Giannini, Laerte Idal Sznelwar, Seiji Uchida e Selma Lancman

\section{NOTA DO EDITOR}

Manuscrito recebido em dezembro/2018

Aceite após peritagem março/2019

\section{Introdução}

1 A Justiça do Trabalho trata especificamente de assuntos relativos ao trabalho e, no Brasil, está inserida no Poder Judiciário desde a Constituição de 1946. Ela contempla 24 Tribunais Regionais do Trabalho (TRT) distribuídos pelo território nacional, sendo o Tribunal Superior do Trabalho (TST) sua instância máxima. Os juízes do trabalho atuam nas Varas do Trabalho e formam a $1^{a}$ instância da Justiça do Trabalho. Quando uma das partes em um processo judicial não concorda com a sentença do juiz de primeira instância, ela pode recorrer da decisão e, assim, o caso segue para a segunda instância da Justiça do Trabalho e passa a ser examinado pelos desembargadores.

2 No Poder Judiciário, incluindo a Justiça do Trabalho, magistrados e servidores são encarregados de interceder e fazer avançar as legislações que regulam os direitos dos 
cidadãos. No entanto, estes mesmos atores, enquanto trabalhadores, vivenciam constrangimentos relacionados ao exercício do seu trabalho que repercutem na realização do trabalho em si, na construção da identidade e, consequentemente, da saúde mental desses profissionais. Ao final, tal repercussão compromete também o avanço das instituições às quais estão ligados, portanto compreender e colaborar com transformações no trabalho desses profissionais é também contribuir para o exercício da cidadania e acesso à justiça social para todos os trabalhadores.

o paradigma utilizado para o projeto da produção e do conteúdo do trabalho no setor público se assemelha ao utilizado no setor privado. Tem-se, como exemplo, a fragmentação dos processos em etapas reduzidas como uma tentativa de simplificação das tarefas e de controle da produção. Não se pode negar que resultados significativos foram obtidos, como a racionalização de processos e de gastos, a homogeneidade dos serviços prestados e os aumentos de produtividade e qualidade. Entretanto, o desafio é construir maneiras de trabalhar em serviços públicos que promovam a saúde dos trabalhadores e o seu desenvolvimento profissional e humano, e, por consequência, promovam também o próprio serviço público. Novos compromissos poderiam ser buscados no trabalhar, por meio da concepção de tarefas e situações de trabalho que aliem as necessidades da produção dos serviços públicos, em termos de qualidade e produtividade, com a promoção da saúde e do desenvolvimento profissional dos servidores.

4 O presente trabalho é parte da pesquisa "Construção da intersetorialidade no campo saúde e trabalho: perspectiva dos profissionais inseridos na rede de serviços do município de São Paulo", fomentada pela FAPESP (Fundação de Amparo à Pesquisa do Estado de São Paulo) e com previsão de término em 2021. Esta pesquisa objetiva compreender como diversos atores que se encontram na linha de frente do campo da saúde e trabalho compõem coletivos intersetoriais e intrasetoriais que permitam o desenvolvimento do trabalho. Nossa hipótese é de que os diversos setores (saúde, trabalho, previdência e justiça) trabalhem de maneira desarticulada entre si (intersetorialmente) e no interior de cada instituição (intrasetorialmente), inviabilizando trocas, avanços no campo e desenvolvimento do próprio trabalho e das profissões envolvidas. Este cenário é agravado pelas modalidades de avaliação de desempenho instituídas nessas instituições públicas.

5 Uma das fases de nossa pesquisa foi elucidar como os magistrados da Justiça do Trabalho em São Paulo participam dessa rede, posicionando o trabalhar destes profissionais na rede intersetorial (com outras instituições) e intrasetorial (dentro da própria instituição a que pertencem). Especificamente, neste artigo, buscamos discutir as redes de cooperação intrasetoriais, isto é, entre pares, que se formam ou não entre os magistrados, para que eles consigam enfrentar o real do trabalho, desenvolver processos cooperativos e colaborativos, avançar regras do oficio e preservar a própria saúde mental. Salientamos que esta pesquisa trata exclusivamente da questão do trabalho na magistratura da Justiça do Trabalho, envolvendo apenas juízes de primeira e segunda instância.

6 A metodologia seguida foi a da Psicodinâmica do Trabalho (PDT) que se insere no campo da pesquisa-ação. Na PDT, o material resultante da pesquisa é construído a partir de discussões coletivas e de um processo reflexivo sobre o trabalhar e da interpretação e da validação desses resultados. Nessa pesquisa, além dos processos 
grupais, foram realizadas entrevistas em profundidade individuais e complementares com os magistrados da Justiça do Trabalho do município de São Paulo, no Brasil.

7 Este artigo está organizado da seguinte maneira: na seção 2 apresentamos os principais conceitos e fundamentos teóricos em que se baseiam a discussão do artigo, à luz da Psicodinâmica do Trabalho: o trabalho prescrito e o trabalho real, o real do trabalho, as dinâmicas de coordenação e colaboração e a dinâmica do reconhecimento. Junto à discussão teórica, outros casos sobre cooperação abordados na literatura são discutidos. Na seção 3, a metodologia de pesquisa da PDT é abordada, bem como instrumentos complementares que foram utilizados. Os resultados dos grupos de reflexão sobre o trabalho e das entrevistas individuais são expostos na seção 4, com foco nas dinâmicas de cooperação para enfrentamento do real. Por fim, a seção 5 traz as discussões finais do artigo e a seção 6, as conclusões e limitações deste estudo.

\section{A cooperação para a psicodinâmica do trabalho}

8 A abordagem da Psicodinâmica do Trabalho (PDT), assim como a da Ergonomia da Atividade, que influenciou os alicerces teóricos dessa disciplina, permite evidenciar as discrepâncias existentes entre o que seria o trabalho prescrito e o trabalho real (efetivo). 0 universo do prescrito engloba as tarefas, que são fruto da expectativa dos gestores e projetistas para se constituir a produção. $O$ trabalho prescrito trata do esperado e do previsto e baseia-se em normas, procedimentos e instruções anteriormente determinadas e entregues a cada trabalhador. Já o trabalho real é o trabalho efetivamente realizado para atingir os objetivos da produção (Daniellou \& Béguin, 2007). A existência de discrepâncias entre o previsto e o real é um dos pontos centrais para a Ergonomia da Atividade e ocorre devido à variabilidade da produção, à diversidade dos trabalhadores, às condições materiais para o desenvolvimento das atividades, às ações não previstas inerentes a qualquer trabalho e aos fenômenos emergentes. $O$ trabalho real se constitui nas ações necessárias para fazer a produção acontecer, que são pautadas nas tradições das profissões, no conhecimento dos diferentes protagonistas, nas competências existentes e no engajamento efetivo destes atores para dar conta das exigências efetivas da produção. A resistência do real àquilo que foi prescrito e às vontades de cada um, a importância dos processos inconscientes que modulam o fazer de cada pessoa e as relações constituídas entre os atores que se expressam em processos dinâmicos de coordenação e cooperação constituem os cenários do trabalhar. Enfim, trata-se do trabalho vivo, onde cada um dá de si através de suas ações para atingir os objetivos da produção e os objetivos que individual ou coletivamente foram definidos (Dejours, 2012).

9 A Psicodinâmica do Trabalho dialoga com o conceito de trabalho prescrito e real da ergonomia, mas, ao estudar os aspectos subjetivos do trabalho, desenvolve o conceito do real do trabalho, pois compreende que o próprio trabalho prescrito se altera com o trabalho efetivo e com os procedimentos formais que o definem, pois nem sempre é possível agir conforme o planejado. Assim, o vivido do trabalho, que inclui o conhecimento, a experiência, as dificuldades e a mobilização da inteligência de cada trabalhador, modifica o trabalhar, entendido como relação indissociável entre trabalhador e trabalho (Dejours, 2012). Ao vivenciar o real, o sujeito mobiliza sua inteligência, sua astúcia, seu corpo e sua capacidade de refletir, interpretar situações e inventar novos caminhos, ou seja, trabalhar nunca é pura execução. Trabalhar é 
exatamente o exercício e as soluções que não foram prescritas pela organização do trabalho para fazê-lo acontecer (Dejours, 2012).

Embora o real do trabalho seja subjetivo e individual, o trabalho não é uma ação singular, apenas composto por justaposições de experiências e de inteligências particulares. Ele é sempre uma relação social e coletiva, pois sempre se trabalha para alguém, para uma outra pessoa, para um patrão, para um chefe, para um cliente (Dejours, 2012). Nesta construção social do trabalhar, há que se coordenar as inteligências de cada trabalhador e engajar sua subjetividade, muitas vezes renunciando-se de parte do potencial individual em prol do coletivo (Dejours, 2012). Assim, o real do trabalho não é o real da tarefa e trabalhar é também experimentar a resistência do mundo social e das relações sociais na implantação da inteligência e da subjetividade. Portanto considera-se que não há no processo de produção um sujeito isolado, uma vez que a importância do coletivo é central (Sznelwar, Uchida, \& Lancman, 2011).

11 Embora a coordenação e cooperação sejam abordadas em praticamente todas as produções de Psicodinâmica do Trabalho, ressaltamos nesse artigo a discussão desenvolvida por Christophe Dejours (2012) no segundo tomo do livro Trabalho Vivo. Paralelamente aos conceitos do trabalho prescrito e efetivo, a Psicodinâmica do Trabalho posiciona a discussão entre a organização do trabalho prescrita, que distribui tarefas entre trabalhadores, denominada de coordenação, e a organização efetiva, que envolve processos de cooperação (Dejours, 2004; 2012), isto é, os trabalhadores reagem à organização prescrita (coordenação) através da organização efetiva (cooperação). A racionalidade que permeia estes dois conceitos é paralela à distância entre o trabalho prescrito e o trabalho real, onde o sujeito mobiliza sua inteligência, sua experiência, seus afetos e seu corpo para vencer e enfrentar uma situação e chegar aos objetivos definidos. Na superação da discrepância entre o que foi previsto e a realidade, a PDT ressalta a coordenação e cooperação como elementos centrais na construção da saúde mental. Como discutido anteriormente, para Dejours (2012) trabalhar vai além de produzir, pois significa viver junto e abdicar de parte do potencial subjetivo individual em prol da cooperação. Portanto, a cooperação exige que uma parte da inteligência e da subjetividade sejam renunciadas pelo bem do coletivo e ela é uma reação à coordenação prescrita pela organização do trabalho.

12 Ao se abrir mão de parte da inteligência individual, de estilos e de engenhosidades singulares, abrem-se caminhos para trocas, que são necessárias para estabilizar a coesão do coletivo de trabalho. Para compensar os riscos de contradição e de conflito entre as divergentes inteligências é forçoso coordená-las. Este processo complicado leva à formação das regras do ofício, que são acordos elaborados pelos membros de um determinado trabalho sobre as maneiras de trabalhar. Esse compromisso supõe que cada trabalhador individualmente compromete-se com o coletivo de trabalho para nele expor sua experiência, suas habilidades, seu saber fazer. As modalidades singulares de trabalho são objeto de confronto, de comparação e de discussão coletiva, que permitem a escolha daquelas mais aceitáveis. Essas regras também são fundamentais para nortear ações individuais que deixam de ser arbitrárias e passam a ser respaldadas e legitimadas por tais acordos coletivos.

13 Essa troca de experiências, habilidades, inteligências e saber fazer de cada trabalhador necessária para a cooperação implica em exposição e visibilidade, ou seja, cada um se expõe e conhece a maneira como o outro trabalha, o que inclui as dúvidas, incertezas, 
inexperiências etc. Trabalhar junto significa discutir e conhecer as diferentes maneiras de trabalhar. A construção do ofício apoia-se na cooperação, quando o trabalho coletivo (maneiras de trabalhar juntos e de ajudar-se mutuamente) está unido ao coletivo do trabalho (Caroly, Loriol, \& Boussard, 2006). O estudo de Caroly e colaboradores (2006) sobre cooperação na polícia francesa conclui que o aprendizado do ofício desses profissionais não termina na formação técnica e requer um trabalho de campo pautado principalmente na troca entre profissionais de gêneros e idades distintos. A construção de regras de ofício é feita pelos trabalhadores a partir de acordos sobre as maneiras de trabalhar e da troca de experiências, a partir do debate acerca de diferentes modos operatórios para a realização da mesma atividade (Dejours, 2012). A cooperação é parte fundamental na preservação e da construção da saúde mental do trabalhador (Caroly et al., 2006) e um dos alicerces essenciais para que se constitua um ambiente de trabalho em que haja confiança naquilo que os outros fazem (Sznelwar et al., 2011).

O estudo de Caroly e colaboradores (2016) demonstra como a complementariedade de habilidades e capacidades entre profissionais de gêneros e idades distintos na polícia francesa torna o trabalho mais eficaz e fluido, além de muitas vezes permitir o apoio moral entre eles em situações desgastantes. Jovens policiais, por exemplo, buscam o apoio e a experiência dos mais experientes para situações complicadas e perigosas, ao mesmo tempo que trazem para o grupo novas formas de realizar o trabalho. Ouvir o conhecimento dos mais velhos não significa apenas a transmissão de histórias, mas também a construção de um sentido compartilhado sobre o trabalho que juntos farão (Caroly et al., 2016). No entanto, um fator que prejudica a cooperação entre policiais é a dificuldade de se falar sobre emoções, já que a cultura policial pressupõe que os profissionais sejam "fortes" e viris (Caroly et al., 2016). Esconder fragilidades, medos e sentimentos é comum entre eles e isto impede a verbalização de dificuldades relacionadas com o real do trabalho. Ainda assim as relações de troca entre policiais de diferentes gêneros e idades possibilitam a construção de um ofício sempre novo onde cada um encontra seu lugar (Caroly et al., 2016).

Para Stettgen, Kohl, Reese Happ e Sischka (2015), que propõem uma maneira para medição da qualidade do trabalho, a cooperação está representada em dois dos vinte e um itens de análise: "você coopera com seus colegas no trabalho?" e "seus colegas te dão suporte no trabalho?", ou seja, ela representa uma parte significativa do que os autores entendem como qualidade do trabalho. Nos estudos de Maceviciute (2014) sobre o setor bibliotecário na Lituânia, de Tudor, Zaharie e Osoian (2014) sobre desenvolvimento de inovação em empresas manufatureiras na Romênia e de Kekkonen, Pohjosenperä, Kantola e Väyrynen (2018) sobre a alocação de tarefas entre equipe de enfermagem e prestadores de serviços de saúde em hospitais na Finlândia, a cooperação entre instituições e entre trabalhadores é considerada importante faceta do trabalho e do atingimento dos resultados esperados para o negócio. É importante destacar que, se a cooperação e o trabalho em equipe são enfatizados nas organizações, eles muitas vezes inscrevem-se na esfera do prescrito e desconsideram a subjetividade e o engajamento envolvido nesse processo. Desconsideram também as condições efetivas para que essa colaboração ocorra no cotidiano do trabalho.

O trabalho de Azevedo e colaboradores (2018) analisa a implantação do modelo de equipe de gestão no setor de hematologia (responsável por atividades de ambulatório, quimioterapia e transplante de medula óssea) de um hospital universitário brasileiro e a importância da cooperação para melhoria da qualidade do cuidado e das relações 
intersubjetivas entre os trabalhadores. No setor, o fortalecimento da equipe multidisciplinar deve-se à sistematização de reuniões semanais para discussão de temas assistenciais, casos clínicos, resultados de congressos, definição de protocolos de quimioterapia e questões administrativas. Segundo a observação de Azevedo e colaboradores (2018), situações delicadas como, por exemplo, passar um paciente para cuidados paliativos, são levadas para a reunião com toda equipe, incluindo profissionais do ambulatório e da enfermaria. Nenhuma decisão delicada é definida por menos de três médicos, para proteção do paciente e melhoria da qualidade do tratamento. Além de apoiarem a atividade assistencial e o ensino, as discussões de casos em grupo também têm o papel de um amparo simbólico para os profissionais, principalmente quando estão envolvidos em decisões de alto impacto para a vida de seus pacientes. As discussões coletivas fortalecem ainda o reconhecimento da contribuição de cada profissional para o coletivo de trabalho e os trabalhadores sentem-se pertencentes a um grupo (Azevedo et al., 2018). Ou seja, o modelo de equipe de gestão implantado no setor tem a dupla vantagem de permitir a expressão da singularidade da experiência dos profissionais e a troca de visões como componentes igualmente fundamentais na decisão clínica. Para os médicos da equipe, o senso e a experiência das colegas são essenciais para seu próprio trabalho pois nem todas as respostas na medicina estão prontas nos livros (Azevedo et al., 2018). Além disso, eventuais falhas em decisões que por ventura não tenham sido as melhores não são atribuídas a um único profissional, pois as deliberações coletivas reforçam o compartilhamento de responsabilidade entre a equipe. Para estes autores, as discussões de casos possibilitam, do ponto de vista da análise dos processos intersubjetivos, a criação de espaços onde a equipe habite um lugar intermediário entre a realidade objetiva das condições clínicas do paciente e a realidade subjetiva de cada profissional que experimentou diversas sensações durante o contato com ele. Nestes espaços, delimitado coletivamente com base em cada uma das exposições sobre o paciente, os profissionais se mantêm em contato com o caso, mas podem também se distanciar dele, o que permite percebê-lo de outras perspectivas. Ao mesmo tempo, podem reconhecer as diferentes maneiras que os colegas têm de sentir, avaliar e prognosticar e, neste trânsito entre presente, passado e futuro, criar projetos terapêuticos singulares (Azevedo et al., 2018).

17 No caso estudado por Azevedo e colaboradores (2018), os mecanismos de cooperação como resposta à organização prescrita (coordenação) são evidenciados pelas reuniões sistemáticas e deliberações coletivas, que possibilitam transparência e debate sobre o real do trabalho destes profissionais. Destaca-se a consideração dos profissionais como parte de uma equipe e como parte das decisões a respeito de seus pacientes, ressaltando-se o reconhecimento das contribuições de cada trabalhador à organização do trabalho, a mobilização de sua inteligência, o seu investimento no trabalho e as responsabilidades e riscos que assume.

A discussão sobre a dinâmica do reconhecimento na Psicodinâmica do Trabalho também é fundamental para que se possa refletir sobre a cooperação no trabalho. Na PDT, fala-se em julgamento e não em avaliação (Dejours, 2012; Molinier, 2013). O reconhecimento passa por dois tipos de julgamentos: o julgamento de utilidade e o julgamento de beleza. o julgamento de utilidade é realizado pela hierarquia e contempla a utilidade econômica, social ou técnica da contribuição feita pelo trabalhador. A utilidade do trabalho é diferente do resultado ou da rentabilidade que são absorvidos pela empresa (Dejours, 2008). o julgamento de beleza anuncia o saberfazer, a "estética" do trabalho e o esforço do trabalhador e é realizado pelos pares, que 
são outros trabalhadores que conhecem a fundo o trabalho realizado (Dejours, 2008; 2012; Molinier, 2013). Por se tratar do julgamento de pares, é a avalição realmente fundamentada no real do trabalho e, portanto, a mais valiosa (Dejours, 2008). 0 sucesso da dinâmica do reconhecimento é dado pela capacidade de tornar os julgamentos de beleza e de utilidade menos contraditórios e mais uniformes possíveis (Molinier, 2013). Ademais, a dinâmica do reconhecimento pressupõe julgamentos e não medições, que são bem diferentes (Dejours, 2008). Estes dois julgamentos são imprescindíveis para os processos de reconhecimento e também para a construção identitária e do sentido do trabalhar.

19 Se entendemos os pares como partes essenciais na dinâmica de reconhecimento, há de se reconhecer que instituições que privilegiam a competição interna percorrem um caminho contrário ao que se entende como formas justas para julgar o trabalho de qualquer profissional. No mesmo sentido, métodos de avaliação pautados no desempenho individual também provocam danos à cooperação, pois colocam os objetivos do indivíduo à frente dos objetivos do coletivo. É importante frisar que os processos de julgamento de beleza e de utilidade só fazem sentido em ambientes propícios à cooperação, uma vez que se tratam de apreciações pautadas em confiança. No entanto, embora a cooperação e o trabalho em equipe sejam valorizados em estudos organizacionais, elas não são termos precisos, ou seja, não fica claro o que se entende por cooperação. Cooperação não se trata de ajuda ou de algo prescrito, pois ela envolve necessariamente processos de confiança, de trocas, de solidariedade e de exposição de habilidades, fraquezas e dúvidas. Os atuais processos de gestão baseados em avaliação individual de desempenho podem destruir a cooperação uma vez que são antagônicas da confiança.

20 À luz dos conceitos da Psicodinâmica do Trabalho expostos nesta seção, este artigo pretende compreender a cooperação no trabalho dos magistrados (juízes e desembargadores) da Justiça do Trabalho no município de São Paulo, Brasil. A metodologia de pesquisa também se baseia no método da PDT, como será apresentada a seguir.

\section{Metodologia de pesquisa}

21 A metodologia utilizada neste artigo foi pautada na Psicodinâmica do Trabalho, que segundo Dejours $(2004 ; 2012)$ e Molinier (2013) se caracteriza como uma pesquisa-ação e como um método clínico de análise. Essa corrente metodológica entende que a produção do conhecimento e a intervenção são indissociáveis e que determinadas compreensões e construções teóricas são realizadas a partir do estudo de situações concretas de trabalho e da escuta dos profissionais envolvidos (Dejours, 2004; 2008; 2012). Trata-se também de um método interativo, onde os atores deixam de ser simplesmente objeto de observação, de explicação ou de interpretação e tornam-se parte integrante da pesquisa, de sua concepção, de seu desenrolar, de sua redação e de seu acompanhamento (Thiollent, 1997).

A pesquisa em Psicodinâmica do Trabalho caracteriza-se como uma pesquisa-ação pelo envolvimento e transformação esperada do sujeito que participa da ação. Ao propor uma escuta clínico-reflexiva realizada em grupos, a PDT favorece trocas e processos de compartilhamento decorrentes da reflexão proposta. Na PDT o material da pesquisa é constituído a partir de reflexões sobre o trabalhar, da análise realizada pelos 
pesquisadores que conduzem os grupos, da produção de um relatório interpretativo e da validação desse material. Todo esse processo é denominado mais comumente entre os "psicodinamistas" como "grupos de reflexão sobre o trabalho". Nesse tipo de investigação, a ação se dá a partir da possibilidade de que os próprios sujeitos se apropriem do sentido do seu trabalho e criem espaços para deliberação de regras, que por sua vez favoreçam mecanismos de cooperação. Os grupos de reflexão não são conduzidos através de roteiros pré-definidos, ao contrário, eles permitem que os participantes naveguem entre temas relevantes por eles escolhidos, que possibilitem maior compressão e apropriação do trabalho. Nesta etapa da pesquisa objetivou-se criar um espaço de discussão onde os magistrados da Justiça do Trabalho pudessem expressar e compartilhar as suas vivências, incluindo impasses, questões, dificuldades e soluções ligadas à experiência do seu trabalhar, favorecendo uma maior apropriação do trabalhar. A realização de entrevistas individuais, como complemento ao trabalho em grupo, fez parte da abordagem no campo.

23 A técnica em PDT consiste em escutar e observar, durante a realização dos grupos, temas consensuais e contraditórios entre os participantes e em considerar também paradoxos e contrastes (Dejours, 2004). O objetivo não é desvendar a realidade e as dimensões físicas e cognitivas do trabalho, mas, sim, entender vivências subjetivas (Dejours, 2004). Para tanto, os pesquisadores se interessam pela dimensão do comentário, que inclui concepções subjetivas, o dito e o não dito, e formulam hipóteses sobre o porquê e o como da relação vivenciada no trabalho, as explicações e até mesmo observações de caráter anedótico. Na pesquisa em PDT o comentário é a matéria-prima, é a formulação da atividade de pensar dos trabalhadores sobre sua situação (Dejours, 2004). Como o foco da pesquisa é a compreensão do coletivo de trabalho, eventuais faltas ou substituições de participantes não impedem o bom andamento dos trabalhos (Dejours, 2004). Após a realização dos grupos, os pesquisadores elaboram um relatório interpretativo que é validado com o grupo de participantes, criando-se assim um processo comunicativo e devolutivo das interpretações formuladas. Em Psicodinâmica do Trabalho, as ações são realizadas necessariamente por mais de um pesquisador, formando assim um coletivo e um processo cooperativo entre pesquisadores e pesquisados, que engloba, comumente, a prática de supervisores "externos" (Dejours, 2004).

24 Como já citado, o trabalho aqui apresentado é parte da pesquisa "Construção da intersetorialidade no campo saúde e trabalho: perspectiva dos profissionais inseridos na rede de serviços do município de São Paulo", fomentada pela FAPESP (Fundação de Amparo à Pesquisa do Estado de São Paulo), onde vem sendo estudado o trabalhar de diferentes profissionais dos órgãos que compõe a rede de saúde e trabalho no Brasil: Ministério da Saúde, Ministério da Previdência Social, Ministério do Trabalho e do Emprego, Ministério Público do Trabalho e Justiça do Trabalho. A pesquisa foi aprovada pelo comitê de ética da Faculdade de Medicina da Universidade de São Paulo (FMUSP) e os participantes assinaram o termo de consentimento livre e esclarecido.

Tem-se observado nessa pesquisa que os diversos setores trabalham de forma fragmentada em ações que envolvem um mesmo objeto e ainda não existem indícios de que os vários setores e profissionais envolvidos realizem parcerias mais formais ou que realizem trocas de informações, acordem o âmbito de suas ações etc. Dado que a cooperação entre instituições parece ser inexistente, buscou-se estudar os setores de 
forma distinta para no final da pesquisa, em 2021, se elaborar uma discussão considerando a rede de instituições em seu conjunto.

$\mathrm{Na}$ etapa apresentada neste artigo, fez-se um recorte no trabalho dos magistrados da Justiça do Trabalho de São Paulo para buscar compreender seu trabalho, sua participação no campo da saúde e trabalho e como eles compõe redes de cooperação internas, ou seja, entre pares. Foram realizadas entre os meses de novembro de 2017 e janeiro de 2018 quatros sessões com magistrados que atuavam há, pelo menos, cinco anos na magistratura do trabalho. Após estas sessões a equipe de pesquisa elaborou um relatório provisório que posteriormente foi validado com os magistrados. Com o processo de validação finalizado, o relatório tornou-se público, podendo ser utilizados pelos magistrados da maneira que lhes for mais conveniente e pelos pesquisadores em publicações e apresentações de cunho acadêmico. Entre os meses de setembro e outubro de 2018, duas entrevistas em profundidade e individuais foram realizadas com dois magistrados que haviam participado dos grupos de reflexão para aprofundamento do tema cooperação. Esse recurso tem sido utilizado em PDT em situações onde temáticas especificas relacionadas à pesquisa não são suficientemente abordadas nos grupos, demandando uma complementação, como foi o caso dessa pesquisa, ou ainda quando se abordam temáticas que possam ser difíceis de serem abordadas em grupo, como por exemplo, questões relacionadas ao suicídio no trabalho. Os resultados aqui apresentados foram retirados deste relatório e das entrevistas.

\section{Resultados}

\subsection{Constituição do trabalhar do juiz do trabalho}

Após o tempo dedicado aos estudos para aprovação no concurso, os juízes são nomeados e recebem treinamento técnico, de aperfeiçoamento e de atualização oferecidos pela Escola da Magistratura. No entanto, apesar de o treinamento ser fundamental para os processos de aprendizagem, não se pode considera-lo como suficiente para que cada um dê conta do real que será enfrentado no dia a dia da profissão.

Resumidamente, o papel do juiz do trabalho é julgar os conflitos apresentados entre as partes (geralmente a empresa ou instituição contratante e o trabalhador contratado) e solucioná-los através de acordos ou sentenças. Os conflitos chegam ao juiz através de petições, documentos e testemunhos apresentados pelas partes e são discutidos durante audiências, com a presença de advogados e testemunhas. Embora haja contato com a matéria a ser julgada ao ler as petições, ao estudar as provas e evidências e ao confrontá-las com a legislação, com a jurisprudência e com as súmulas vinculantes, o real do trabalho do juiz se dá de modo significativo durante as audiências. É no dia a dia das audiências que o juiz une as informações que entende como necessárias (provas, depoimentos), confronta a veracidade de depoimentos e testemunhos buscando confirmações, esclarecimentos e contradições para propor conciliações (acordos) ou para proferir a sentença.

O trabalhar do juiz vai, portanto, muito além da leitura de provas e da escuta das partes e de testemunhas. A constituição da percepção e dos sentimentos que vivenciam são parte fundamental da construção da sensibilidade do magistrado. Tal sensibilidade, aliada à sabedoria prática e à astúcia, permite que cada um se torne mais convicto sobre 
o que é verídico em cada caso. A partir daí o magistrado faz um juízo sobre suas impressões acerca da sinceridade, da veracidade ou da mentira expressas pelas partes, sobre os diferentes pontos de vista, sobre a consistência das provas e sobre a relação específica entre os fatos, o direito e a jurisprudência, para aplicar a lei da melhor forma possível. O seu entendimento daquilo que é justo em cada caso é sempre uma vivência específica e não há casos iguais, apesar de poder haver semelhanças entre as matérias julgadas na Justiça do Trabalho.

O trabalhar do juiz envolve o corpo, o estar presente e engajado na audiência para poder enriquecer o seu ponto de vista. Não se trata de um trabalhar pautado em um procedimento padronizado e anteriormente determinado. Trata-se de um trabalhar sensível, que exige apreciação e engajamento em cada situação particular, onde cada um age de um modo compreensivo e singular na hora de lidar com as partes e testemunhas. Construir a sua convicção é também um trabalho que exige criatividade, pois o trabalho não é apenas aplicar a lei pautado no texto legal, mas compreender e interpretar o que aquelas pessoas vivenciaram e buscar ser o mais justo possível. Portanto, ser juiz é uma arte, a de saber conduzir as audiências, de compreender o que há de evidências nos autos e de ser criativo na hora de sentenciar e de aplicar a lei de modo justo.

Então, se o trabalhar do juiz constitui-se fundamentalmente no respeito ao senso de justiça mais que da aplicação técnica da lei, o erro é expresso no receio de não conseguir julgar de modo justo. Uma das questões que se coloca é que, apesar de exercerem um papel fundamental na construção da justiça, eles não têm condições de tudo saber, são falíveis e, portanto, podem errar. Adicionalmente, os magistrados lidam com a existência de ao menos duas (ou eventualmente mais) diferentes linhas de posicionamento para um mesmo caso. A adoção de uma abordagem específica pelo magistrado não é instituída pela organização, é uma questão de posicionamento individual, de entendimento, da visão de cada profissional frente às possibilidades apresentadas. Os magistrados reconhecem o sentimento de injustiça quando uma parte reclamante recebe uma sentença favorável e uma outra parte, com processo similar, recebe sentença desfavorável, porque foram julgadas por dois juízes com posições diferentes. Ou seja, embora escolher e adotar posicionamentos distintos seja legítimo, há uma ansiedade frente ao sentimento de injustiça que a existência de diferentes abordagens pode causar. Em especial, o sentimento de injustiça ou de incoerência aparece quando o próprio magistrado percebe que, com base em novas experiências, em novos conhecimentos, em novas vivências, ele mesmo optou por uma abordagem diferente daquela adotada em processos anteriores. 0 trabalhar do juiz não é matemático nem exato e o desafio intelectual está justamente na busca cotidiana pelo justo, pelo que julga coerente segundo suas convicções, leis e evolução da jurisprudência. Para os magistrados, sentir que há coerência entre suas próprias sentenças é importante para a sensação de trabalho bem-feito. Quando se veem frente a um caso que os leva para uma decisão contrária a decisões seguidas anteriormente em casos semelhantes, sentem-se incoerentes frente à própria mudança de percepção. Isto mostra uma das questões-chave da vivência desses profissionais, expressa em um certo isolamento devido às próprias modalidades de organização do trabalho, onde o compartilhamento de pontos de vista e o retorno da experiência não são sistematicamente realizados, deixando-os sozinhos com suas decisões, dúvidas, percepções. 

causada pela própria organização do trabalho, já que cada juiz é, em geral, o único atuante em cada vara, exercendo sozinho todo o trabalho de interpretação de fatos, condução de audiências e sentenciamento. Não há mecanismos institucionais que reforcem as trocas entre juízes, que permitam dar mais guarida a processos que valorizem o retorno da experiência e onde cada um possa expor o seu modo de trabalhar, compreender, interpretar e discutir as suas dúvidas e dificuldades e dar maior visibilidade ao trabalho. É verdade que existem os cursos, a participação em comissões e os esforços da Escola Judicial em promover maior integração, mas não se tratam de mecanismos institucionais propícios ou suficientes para se criar uma tradição de compartilhamento, de cooperação, ou seja, um efetivo coletivo de trabalho. 0 trabalho do juiz de primeira instância se caracteriza pelo pouco contato formal com os colegas, com quem os contatos se resumem aos momentos em que se encontram em lugares de refeição ou em algum curso. Isto reforça a não existência de uma política institucional para promover as trocas e as possibilidades de discutirem as vivências no trabalho.

35 A solidão também é reforçada pela competição entre juízes. Há algo muito sutil que diz respeito à relação com os pares: por exemplo, a distribuição de processos mais difíceis ou maçantes ao juiz substituto durante férias ou licença do titular, que pode ser um sinal de descompromisso com os colegas e com a própria instituição, com consequências para a própria profissão. Fica evidente que aqueles que o fazem procuram dar conta de soluções mais imediatas em detrimento do que seriam os verdadeiros desafios da profissão que exigiriam maior engajamento. Ademais, é comum que haja um julgamento depreciativo entre os próprios magistrados, feito muitas vezes sem o conhecimento dos mesmos (pelas costas). Cria-se um processo de "fama", que pode ter a ver com aqueles que são mais exigentes, mais condescendentes ou mais conciliadores, por exemplo. 0 incômodo é que este estereótipo reforça a parte ruim do trabalho e os comentários que possam enaltecer o trabalho de um juiz não o integram.

\subsection{0 ciclo da solidão e da autoavaliação}

Devido ao isolamento e à ineficácia dos mecanismos formais de avaliação de desempenho, a tendência à autoavaliação pode ser considerada como uma maneira para considerarem a qualidade do próprio trabalho. Tal tendência é fruto do modo como é organizada a produção e a avaliação no Poder Judiciário, que impõe metas incoerentes com o sentido do trabalho e não traz instrumentos para institucionalizar o 
julgamento de beleza realizado pelos pares e para considerar a utilidade daquilo que fazem. objetivos exclusivamente individuais, existem mecanismos de solidariedade e de cooperação que os juízes desenvolvem com seus pares. Há redes de cooperação que são criadas informalmente, com sua constituição facilitada pelas tecnologias de comunicação e uso de celulares e aplicativos específicos para tal fim.

prestando o concurşo público, arguição oral, que é a última etapa do processo seletivo. Neste momento, eles não são mais concorrentes entre si, pois a aprovação independe do número de vagas e de candidatos. Esta etapa é também a que gera maior ansiedade entre os candidatos, que serão avaliados em conhecimentos técnicos e em habilidades para lidar com o público por uma banca gabaritada. Muitos frequentam os mesmos cursinhos preparatórios e os elos de confiança e intimidade que se criam durante esta etapa são muito fortes, emergindo relações francas e sem pudores quanto a dúvidas, erros e inquietações. Esta fase da carreira contrasta com a fase seguinte, quando, já juízes, sentem no dia a dia a obrigação de serem infalíveis e de tudo saberem, já que são fomentadores da justiça, mesmo quando em muitos momentos sentem necessidade de desabafar ou buscar ajuda para as situações fora do comum, como quando enfrentam casos com muitas peculiaridades que os tornam especiais para julgar. Para o juiz do trabalho, a intimidade criada com os pares durante um momento difícil para todos eles (a espera pela arguição oral) estreita os laços de confiança e cooperação e elimina julgamentos depreciativos perante situações que possam ser banais. Estas redes são reforçadas na etapa do processo formativo conduzido pela Escola Judicial aos magistrados que 
acabam de assumir a posse. Os colegas de turma tornam-se ao longo dos anos as principais referências para os juízes do trabalho.

As redes informais podem diminuir o sofrimento no trabalho e contribuir no estabelecimento de estratégias defensivas. A questão do sofrimento no trabalho e da constituição de estratégias defensivas foram abordadas no decorrer da pesquisa e apresentadas no relatório enviado ao órgão de amparo (FAPESP), mas não foram priorizados na discussão sobre os mecanismos de coordenação e cooperação, foco deste artigo, e por isso não foram exploradas em profundidade neste documento. Estes temas também são analisados e discutidos na pesquisa "Trabalhar na magistratura, construção da subjetividade, saúde e desenvolvimento profissional" (Sznelwar et al., 2015).

\section{Discussão}

Como foi exposto na apresentação dos resultados, a organização do trabalho a que estão submetidos os magistrados da Justiça do Trabalho em São Paulo induz a um trabalho solitário e com poucas possibilidades de trocas. Ainda assim, estes profissionais conseguem estabelecer redes de cooperação que orientam o enfrentamento do real do

Laboreal, Volume $15 N^{\circ} 1$ | 2019 
trabalho. A constituição de redes de cooperação em um ambiente aparentemente hostil para tanto é o ponto central de discussão deste artigo.

51 A cooperação pode se dar de diferentes maneiras e a organização do trabalho pode contemplar processos cooperativos ou não. No caso dos juízes do trabalho do município de São Paulo no Brasil, o cotidiano do trabalho se caracteriza por ações individuais onde cada magistrado em sua vara exerce seu papel. Dessa maneira, as trocas e processos cooperativos ocorrem formalmente apenas em reuniões e treinamentos esporádicos organizados pelo tribunal. Todavia isto não significa um verdadeiro retorno da experiência e ainda menos um processo de discussões e deliberações sobre o trabalhar e sobre suas regras. Ademais, a avaliação de desempenho é individual e com base em medidas quantitativas, o que acirra a comparação e concorrência entre pares.

As redes de confiança constituídas entre os magistrados do trabalho podem ser consideradas como um exemplo interessante para os conceitos de cooperação e coordenação discutidos por Dejours (2012). A organização prescrita do trabalho dos juízes pressupõe que o trabalhar de cada magistrado tenha um caráter essencialmente individual, já que cada juiz é, em geral, o único atuante em cada vara, com metas exclusivamente individuais. Oficialmente, não há mecanismos institucionais que reforcem as trocas entre juízes, ou seja, todo o trabalho de interpretação de fatos, condução de audiências e sentenciamento é feito isoladamente sem coordenação com seus pares. Os juízes reagem à organização prescrita com a criação de redes informais, que materializam a cooperação entre eles. Por não serem instrumentos institucionais, a construção destas redes se dá pelas condições que os magistrados vivenciam em seu dia a dia. 0 primeiro elo que criam com seus pares acontece entre a penúltima e última etapa do concurso público, quando não se veem mais como concorrentes e dividem as angústias e ansiedades pela aprovação na magistratura e início de carreira. Outros elos também podem ser criados no decorrer de suas carreiras com colegas que trabalham próximos e eventualmente compartilhem afinidades, embora estas relações sejam menos frequentes. Os grupos apoiados pelo uso de aplicativos de comunicação nos celulares são rápidos e eficientes para constituir, ao menos parcialmente, os laços de cooperação.

Apesar da importância e legitimidade destas redes, elas não substituem dispositivos institucionais que poderiam ser aprimorados para propiciar o retorno da experiência e favorecer a cooperação entre os trabalhadores do sistema judiciário brasileiro. Em relação aos espaços formais, a organização do trabalho atual na magistratura do trabalho não contempla mecanismos legitimados para construir processos de retorno da experiência do trabalho, que também serviriam para a construção de confiança mútua. Este cenário é agravado pelas modalidades de organização do trabalho que isola as ações e pela competição entre pares. Os fóruns existentes não privilegiam a discussão de casos (tanto de casos encerrados quanto dos que estão em andamento), como acontece no caso estudado por Azevedo e colaboradores (2018) no setor de hematologia de um hospital universitário brasileiro, citado anteriormente. Azevedo e colaboradores (2018) destacam em seu estudo a importância da organização de reuniões sistemáticas e de espaços formais e institucionalizados no setor, que acontecem com o intuito de discutir casos e acordar linhas de intervenção e contribuem para que haja compartilhamento dos riscos e das inquietações sobre as decisões que precisam fazer.

Diferentemente de equipes médicas que trabalham em conjunto no mesmo caso, os juízes do trabalho são responsáveis individualmente por seus casos. No entanto, a 
oportunidade de discutir e compartilhar casos complicados e peculiares contribuiria com a troca de dúvidas, experiências e soluções, favorecendo ações deônticas, que subsidiariam condutas futuras. Diversos autores (Dejours, 2012; Molinier, 2013) demonstram a importância destes espaços na constituição de estratégias para lidar com o sofrimento decorrente do trabalho e na coletivização de dúvidas e decisões. Tanto nas ações de saúde como nas ações da justiça, as decisões não se articulam apenas por intermédio de instrumentos normativos, tornando-se essencial explicitar as conexões entre as intervenções e reconhecer as diferenças entre os profissionais para que as ações possam levar à melhoria da qualidade do serviço e promover a saúde mental dos trabalhadores (Azevedo et al., 2018).

55 A constituição de uma profissão depende da possibilidade de fazer parte de determinado coletivo baseado em regras mais ou menos estáveis. Essa contribuição de cada trabalhador para o enriquecimento da profissão reforça a identidade de cada um e é fundamental na realização de si e na busca da saúde (Sznelwar et al., 2011). Na magistratura, além da ausência de mecanismos formais que incentivem a cooperação, os métodos de avaliação individual com base em informações quantitativas estimulam a competição entre pares, provocando danos na confiança entre eles. Um exemplo deste processo que deteriora a confiança é a distribuição de casos mais difíceis ou que demandam mais tempo ao juiz substituto durante as férias ou licença do titular. Esta prática evidencia o intuito de dar conta dos processos mais fáceis, mais rápidos e que facilitam o alcance de metas quantitativas, em detrimento do que seriam os verdadeiros desafios da profissão e que exigiriam um maior tempo e engajamento. É fato que, em alguns casos específicos, alguns juízes dividem o tempo de seus assistentes que por ventura esteja ocioso para "desafogar" os colegas que estão com muito trabalho acumulado. No entanto, esta reorganização da equipe não é formal ou incentivada e trata-se de exceções, que acontecem em casos particulares quando há relação de amizade e confiança entre dois ou mais juízes. No dia a dia, os magistrados estão muito atarefados e preocupados em dar conta das suas metas de produção e compartilhar não ajudaria, em princípio, a melhorar o desempenho individual e coletivo, podendo até ser considerado como tempo perdido, como um empecilho para atingir as metas.

É interessante notar que as redes de cooperação na magistratura do trabalho são constituídas, em sua maioria, por profissionais que ingressaram na profissão no mesmo momento, aprovados no mesmo concurso, e tais redes acompanham os juízes no desenrolar de suas carreiras. Diferentemente do que demonstra Caroly e colaboradores (2016) a respeito da importância da troca de experiência entre profissionais com idades distintas na polícia francesa, não há evidências de que os juízes compartilhem experiências com profissionais com mais tempo de profissão ou que discutam as maneiras de trabalhar com profissionais mais jovens. Ao contrário, as redes de cooperação entre os juízes mantêm-se entre aqueles que estudaram juntos e que têm o mesmo tempo na profissão.

Ainda com respeito ao estudo de Caroly e colaboradores (2016), uma faceta do trabalho da polícia francesa pode representar o mesmo impeditivo para que os magistrados em São Paulo evitem as redes de cooperação: a dificuldade de se abrir com relação a sentimentos e dificuldades, ou ainda com relação a certas artimanhas que usam para dar conta do trabalho a ser realizado. Tanto policiais como magistrados se forçam a manter uma aparência de profissional infalível, o que prejudica a troca de experiências. 
58 relações de confiança entre pares, inclusive entre aqueles que têm diferentes tempos de experiência e poderiam enriquecer a construção da profissão na magistratura. Também poderiam permitir aos juízes a construção de maior coesão e clareza na discussão sobre as modalidades da organização do trabalho com instâncias superiores, visando processos de transformação efetivos. Este tipo de espaço para estímulo da cooperação seria essencial também para constituir e consolidar mecanismos de julgamento da beleza do seu saber-fazer, que só pode ser feito por pares, por aqueles que conhecem a fundo como é o trabalhar. o julgamento do trabalho do magistrado não se trata apenas de avaliar a qualidade de uma sentença, mas de colocar frente aos pares o que fazem, como fazem, permitindo efetivamente uma avaliação da qualidade e do esforço de cada um. $O$ julgamento de beleza enaltece o saber fazer e a mobilização da inteligência e do corpo e vai muito além da avaliação de resultados de um trabalho. A avaliação é desejada pelos trabalhadores (Dejours, 2008) e as pessoas têm reações mais negativas frente a incertezas geradas por não serem avaliadas e não saberem como estão contribuindo para que o trabalho aconteça (Goler, Gale, \& Grant, 2016). Mais ainda, a esperança pelo reconhecimento oriundo de processos avaliativos que reflitam o trabalhar e o esforço de cada um é um dos pilares da motivação no trabalho (Molinier, 2013). No entanto, essa avaliação precisa refletir o que as pessoas fazem do ponto de vista qualitativo. $O$ ciclo de autoavaliação legitimado pelos juízes do trabalho é reflexo da ausência de reconhecimento pelos pares, hierarquia e partes envolvidas no trabalhar, uma reação à falta de mecanismos formais que reconheçam o esforço dispendido no trabalho e da importância de se criar espaços de trocas.

A criação e incentivo de redes de cooperação são delicadas. Constituir um ambiente de confiança entre os trabalhadores é um longo processo e destrui-lo é aparentemente muito rápido e relativamente fácil (Sznelwar et al., 2011). A implantação de mecanismos que reforcem a concorrência e a competição entre pares, como é o caso dos modelos de avaliação de desempenho individual, pode se constituir em um processo de destruição da solidariedade entre os indivíduos. 0 investimento em sistemáticas institucionais, com a constituição de dispositivos para troca de experiências e de coletivos nos quais os profissionais possam criar formas de solidariedade e de cooperação no trabalho mostra-se essencial para construção da saúde do trabalhador e melhoria da qualidade de seus serviços. Porém, isto só é possível se, na pauta, estiverem previstas transformações profundas na organização do trabalho e nas modalidades de avaliação de desempenho de magistrados e servidores. A resolução $n^{\circ} 240$ do Conselho Nacional de Justiça abre uma perspectiva interessante a respeito (Conselho Nacional de Justiça, 2016).

\section{Conclusões}

Neste artigo, buscou-se discutir a importância dos mecanismos de cooperação, que podem favorecer tanto o reforço da identidade profissional, como os processos de construção da saúde e da realização profissional dos juízes do trabalho. Em se tratando de processos subjetivos, mas sobretudo, intersubjetivos, os mecanismos de cooperação são pautados na confiança e na construção de algo comum à profissão. $O$ trabalho do magistrado da Justiça do Trabalho é caracterizado pela falta de mecanismos formais de colaboração e pela existência de mecanismos informais que se constituem entre pares

Laboreal, Volume $15 N^{\circ} 1$ | 2019 
(cooperação) e que servem para responder à necessidade de trocas e experiências para a construção de um mundo profissional compartilhado. Mesmo reconhecendo a importância de tais mecanismos informais, fica evidente que eles não substituem os que poderiam ser criados institucionalmente. Mais ainda, a organização do trabalho adotada atualmente no Sistema Judiciário reforça os mecanismos de avaliação individual de desempenho pautados exclusivamente nos resultados do trabalho, sobretudo quanto ao cumprimento de metas. Ou seja, os magistrados da Justiça do Trabalho de São Paulo estão organizados em um modelo que não incentiva nenhum tipo de troca com seus pares, mas ainda assim encontram formas alternativas para estabelecer elos de confiança e redes de cooperação para enfrentamento do real.

Os aspectos abordados nesse artigo revelam-se bastante significativos e podem dizer respeito a outros setores da produção dos serviços públicos, onde os espaços para a construção da cooperação não são reconhecidos como importantes nem privilegiados. Entende-se como limitação desta pesquisa o fato de ela não ser automaticamente replicável para outros setores da produção, pois o entendimento dos mecanismos de coordenação e cooperação são particulares a cada profissão.

Acredita-se que ainda há muitas pesquisas para reforçar o que foi proposto como debate neste texto. Todavia, as evidências aqui mostradas ressaltam a importância de se agir para a construção de mudanças que resgatem a importância do trabalho na construção da saúde mental. Com relação ao futuro da pesquisa, pretendemos entender como se dá a cooperação interna nos demais setores que compõem o escopo do projeto, para posteriormente constituir um debate sobre a intersetorialidade no campo de saúde e trabalho em São Paulo e sobre as possíveis redes de coordenação e cooperação entre diferentes instituições. Este trabalho limita-se àquilo que foi possível evidenciar a partir das discussões que foram desenvolvidas ao longo dos grupos e das entrevistas realizadas. Portanto, a continuidade dos trabalhos de pesquisa no campo, assim como a realização de outras que considerem as modalidades de organização do trabalho e de avaliação de desempenho instituídas em instituições públicas, como o Sistema Judiciário Brasileiro, é muito importante. A contribuição das ciências do trabalho, como a Psicodinâmica do Trabalho, pode ser muito significativa para mudar cenários desoladores e propícios à emergência de sofrimento patogênico.

\section{BIBLIOGRAFIA}

Azevedo, C., Miranda, L., Sá, M., Grabois, V., Matta, G., \& Cunha, M. (2018). Entre protocolos e sujeitos: qualidade do cuidado hospitalar em um serviço de hematologia. Cadernos de Saúde Pública, 34(6). https://doi.org/10.1590/0102-331x00043817

Caroly, S., Loriol, M., \& Boussard, V. (2006). Colectivo de trabajo y reglas de oficios. Cooperación entre jóvenes y viejos, hombres y mujeres en las brigadas de Policía de socorro. Laboreal, 2(2), 6-18. http://laboreal.up.pt/revista/artigo.php?id=37t45nSU5471122785416828:1 
Conselho Nacional de Justiça (2016). Resolução $n^{\circ} 240$, de 9 de setembro: dispõe sobre a Política Nacional de Gestão de Pessoas no âmbito do Poder Judiciário. Retirado de http://www.cnj.jus.br/images/ atos_normativos/resolucao/resolucao_240_09092016_29102018182402.pdf

Daniellou, F., \& Béguin, P. (2007). Metodologia da ação ergonômica: abordagens do trabalho real. In Falzon, P. (Ed.), Ergonomia (pp. 281-301). São Paulo: Blucher.

Dejours, C. (2004). Da Psicopatologia à Psicodinâmica do Trabalho. Rio de Janeiro: Paralelo 15.

Dejours, C. (2008). A avaliação do trabalho submetida à prova do real. São Paulo: Blucher.

Dejours, C. (2012). Trabalho e emancipação (Trabalho Vivo, tomo II). Brasília: Paralelo 15.

Goler, L., Gale, J., \& Grant, A. (2016, November). Let's Not Kill Performance Evaluations Yet. Harvard Business Review, pp. 90-94. Retrieved from https://hbr.org/2016/11/lets-not-killperformance-evaluations-yet

Kekkonen, P., Pohjosenpera, T., Kantola, H., \& Vayrynen, S. (2018). Rational and participative task allocation between the nursing staff and the logistics support service provider in healthcare. Human Factors Management, 28, 117-129. https://doi.org/10.1002/hfm.20728

Maceviciute, E. (2014). The Library Sector in Lithuania at the Beginning of the Twenty-first Century. Library Trends, 63(2), 252-266. https://doi.org/10.1353/lib.2014.0038

Molinier, P. (2013). o trabalho e a psique - uma introdução à psicodinâmica do trabalho. Brasília: Paralelo 15.

Sznelwar, L. I., Lancman, S., Uchida, S., Pereira, L., \& Barros, J. (2015). Trabalhar na magistratura, construção da subjetividade, saúde e desenvolvimento profissional (Série Justiça Pesquisa). Brasília: Conselho Nacional de Justiça.

Sznelwar, L. I., Uchida, S., \& Lancman, S. (2011). A subjetividade do trabalho em questão. Tempo Social: Revista da Sociologia da USP, 23(1), 11-30.

Steffgen, G., Kolh, D., Reese, G., Happ, C., \& Sischka, P. (2015). Quality of Work: Validation of a New Instrument in Three Languages. International Journal of Environment Research and Public Health, 12, 14988-15006. https://doi.org/10.3390/ijerph121214958

Thiollent, M. (1997). Pesquisa-ação nas organizações. São Paulo: Atlas.

Tudor, A., Zaharie, M., \& Osoian, C. (2014). Innovation development needs in manufacturing companies. Procedia Technology, 12, 505-510. https://doi.org/10.1016/j.protcy.2013.12.522

\section{RESUMOS}

A cooperação é parte fundamental na construção da saúde mental do trabalhador e pilar essencial para a constituição de um ambiente de trabalho em que haja confiança no trabalho realizado por todos. 0 objetivo deste artigo é discutir as redes de cooperação que existem no trabalhar dos juízes do trabalho e os impactos que elas exercem no enfrentamento do real. Embora as modalidades formais de avaliação de juízes sejam basicamente quantitativas e individuais e não haja mecanismos institucionais que reforcem as trocas entre pares e valorizem o retorno da experiência, observa-se a criação de redes entre colegas. 0 artigo é parte da pesquisa "Construção da intersetorialidade no campo saúde e trabalho: perspectiva dos profissionais inseridos na rede de serviços do município de São Paulo", fomentada pela FAPESP. A metodologia de pesquisa é pautada nos conceitos da Psicodinâmica do Trabalho. 
La cooperación es una parte fundamental de la construcción de la salud mental del trabajador y un pilar esencial en la construcción de un ambiente de trabajo en que haya confianza. El objetivo de este artigo es discutir las redes de cooperación que existen en el trabajo de los jueces en materia laboral y los impactos que ejercen en el enfrentamiento de lo real. Aunque las modalidades formales de evaluación de los jueces sean fundamentalmente cuantitativas e individuales y que no haya mecanismos institucionales que refuercen los intercambios entre pares ni que valoricen la experiencia, se observa la creación de redes entre colegas. El artigo forma parte de la investigación "Construcción de la intersectorialidad en el campo salud y trabajo: perspectiva de los profesionales en la red de servicios del municipio de São Paulo", promovida por FAPESP. La metodología se guio por los conceptos de la Psicodinámica del Trabajo.

La coopération est un élément fondamental de la préservation et de la construction de la santé mentale des travailleurs ; elle est également essentielle dans la création d'un environnement de travail où règne la confiance. Le but de cet article est d'analyser les réseaux de coopération existants dans le travail des juges du travail et leurs effets dans la gestion du réel. Bien que les modalités d'évaluation dans le système judiciaire brésilien soient fondamentalement quantitatives et individuelles, et qu'il n'existe aucun mécanisme institutionnel qui renforce les échanges entre pairs et valorise le retour d'expérience, l'existence de réseaux de coopération créés de manière informelle est un fait notoire. L'article reprend la recherche "Construction de l'intersectorialité dans le domaine de la santé et du travail: perspective des professionnels insérés dans le réseau de services de la ville de São Paulo", soutenue par la FAPESP. La méthodologie est basée sur les concepts de la psychodynamique du travail.

Cooperation is a fundamental part of the construction of the workers' mental health and an essential pillar for building a work environment where there are trust at work. The objective of this paper is debating the formal and the informal cooperation networks which exist in the work of labor judges and the impacts they exert in facing the real work. Although the formal evaluation methods of judges are basically quantitative and individualist and there are no institutional mechanisms which reinforce the peer-to-peer exchanges and value the return of experience, we can observe the creation of cooperation networks within peers. This paper is part of the research "Constructing intersectorality in the field of occupational health: Perspective of Professionals in the Services Network of the City of São Paulo", sponsored by FAPESP. The methodology is based on the concepts of Psychodynamics of Work.

\section{ÍNDICE}

Palabras claves: psicodinámica del trabajo, cooperación, magistratura, trabajo real, construcción de salud

Keywords: psychodynamics of work, cooperation, magistracy, real work, health construction

Palavras-chave: psicodinâmica do trabalho, cperação, magistratura, trabalho real, construção de saúde

Mots-clés: psychodynamique du travail, coopération, magistrature, travail réel, construction de la santé 


\section{AUTORES}

\section{RURI GIANNINI}

Departamento de Engenharia de Produção, Escola Politécnica da Universidade de São Paulo (USP); Av. Prof. Luciano Gualberto, 1380 - Butantã, São Paulo, 05508-010;

ruri.giannini@gmail.com

\section{LAERTE IDAL SZNELWAR}

Departamento de Engenharia de Produção, Escola Politécnica da Universidade de São Paulo (USP); Av. Prof. Luciano Gualberto, 1380 - Butantã, São Paulo, 05508-010; laertesz@usp.br

\section{SEIJI UCHIDA}

Instituto de Psicologia, Universidade de São Paulo (USP); Rua Itacolomi, 333, conjunto 45 -

Higienópolis, São Paulo, 01239-020; sjuchida@gmail.com

\section{SELMA LANCMAN}

Faculdade de Medicina, Universidade de São Paulo (USP); Rua Cipotanea, 51, Butantã, São Paulo, 05360-160; lancman@usp.br 